\title{
Marginalisasi Ojek Pangkalan dalam Iklan Grab Versi \#PilihAman
}

\section{Fani Zafira Suryani}

Program Studi Komunikasi, Universitas Muhammadiyah Yogyakarta Indonesia fanizafira4567@gmail.com

\section{Navika Dwi Nurfariza Hermawan}

Program Studi Ilmu Komunikasi, Universitas Muhammadiyah Yogyakarta, Indonesia navikafariza@gmail.com

Diserahkan: 4 Juni 2020; Direvisi: 26 Maret 202 1; Diterima: 26 Maret 2021

\begin{abstract}
This research was made to make the public aware that there are still marginalization practices in this advertisement that we are not aware of. With this advertisement, it is detrimental to the base motorcycle taxi because of the assumption or perception that is formed from this advertisement so that people can turn away and use online motorcycle taxis. In this advertisement the base motorbike taxi is described as not having good safety in driving and also in maintaining the motorbike. This study uses the semiotics method by Roland Barthes, which develops from Ferdinand De Saussure's thinking to analyze the object of research in Grab advertisements. The purpose of this study was to determine the marginalization of motorbikes in the safe select version of the Grab ad. Based on the findings and discussions in this study, the Grab \#PilihAman advertisement has marginalized ojek pangkalan through several things, namely security systems, driver information, and well-maintained motorbikes.
\end{abstract}

Keywords: Grab \#PilihAman, Marginalization, Motorcycle Taxis, Semiotic.

\begin{abstract}
Abstrak
Penelitian ini dibuat untuk menyadarkan masyarakat bahwa masih adanya praktik marjinalisasi dalam iklan ini yang tidak kita sadari. Dengan adanya iklan tersebut merugikan pihak ojek pangkalan karena anggapan atau persepsi yang terbentuk dari adanya iklan ini sehingga orang dapat berpaling dan menggunakan ojek online. Dalam iklan ini ojek pangkalan digambarkan tidak memiliki keselamatan yang baik dalam bergendara dan juga perawatan motor. Penelitian ini menggunakan metode semiotika oleh Roland Barthes yang mengembangkan dari pemikiran Ferdinand De Saussure untuk menganalisis objek penelitian dalam iklan Grab. Tujuan dari penelitian ini untuk mengetahui marginalisasi ojek pangkalan yang terdapat pada iklan Grab versi pilih aman. Berdasarkan temuan dan diskusi dalam penelitian ini, iklan Grab \#PilihAman telah memarginalisasi ojek pangkalan melalui beberapa hal yaitu sistem keamanan, informasi pengendara, dan motor yang terawat.

Kata Kunci: Grab \#PilihAman, Marginalisasi, Ojek Pangkalan, Semotika.
\end{abstract}




\section{PENDAHULUAN}

Marginalisasi memiliki arti yaitu usaha untuk membatasi atau pembatasan, contoh marginalisasi yaitu pemegang modal besar membuat suatu produksi tanpa melihat kelas sosial lainnya yang berubah menjadi kegiatan kapitalis. Mode of production kapitalis menciptakan pasar untuk tenaga kerja, ketimbang hubungan manusia tuan secara tradisional (Faqih, 2002). Iklan merupakan salah satu cara untuk memperkokoh kegiatan kapitalisme. Iklan adalah produknya (barangnya, pesannya, bendanya), sementara periklanan adalah proses kegiatan, mulai dari merancang, membuat hingga kampanye iklan ke masyarakat (Kriyantono, 2013).

Salah satu penggunaan iklan di era digital yaitu melalui tagae yang terdapat pada iklan moda transportasi ojek online yaitu Grab. Salah satu produk dari Grab sendiri adalah Grab Bike atau yang biasa kita tau sebagai ojek motor berbasis aplikasi. Grab yang mengiklankan produk jasanya, meggunakan model wanita sebagai objek promosi. Pada iklan tersebut wanita yang bercita-cita menjadi penyanyi digambarkan jika memilih menggunakan ojek pangkalan maka wanita itu akan berdarah dan terluka. Pada akhirnya, memilih menggunakan transportasi Grab karena dinilai lebih aman dan tidak mengganggu masa depan wanita tersebut. Iklan ini muncul sejak tahun 2016 dan disiarkan di Televisi dan Youtube dengan durasi iklan selama 46 detik.

Cara pemesanan Grab Bike sendiri dapat dilakukan melalui aplikasi yang telah terpasang di gawai para penggunanya, kemudian dapat memilih titik jemput dan titik tujuan maka secara otomatis akan muncul kalkulasi tarif yang harus dibayarkan. Selain itu terdapat juga pilihan cara pembayarannya, dapat dilakukan secara tunai dan secara electronic money. Fitur lain yang ditawarkan adalah pengemudi yang akan mengantarkan pelanggan terdaftar secara resmi di aplikasi Grab dan perjalanan yang dilakukan tercatat atau terekam dalam sistem aplikasi juga. Dengan demikian, pelanggan merasa lebih aman dari segi tarif dan perjalanan yang dilakukan. Informasi pengemudi yang akan mengantar pelanggan disertai nomor telepon dan sarana pesan.

Melihat kondisi saat ini dimana iklan yang ada di ruang publik sangat massif membuat para pengguna jalan yang melintas dapat melihatnya secara berulang-ulang dan diharapkan menimbulkan awearness. Dengan demikian, apa yang disampaikan melalui iklan tersebut dapat sampai dan selalu diingat oleh para pengguna jalan yang mana itu adalah target dari iklan itu sendiri. Iklan yang bersifat persuasif atau kata lainnya menarik perhatian kita semua, karena berada dihampir setiap tempat manusia itu berada (Potter, 2014). Sebuah perusahaan global yang menyediakan pemahaman komprehensif pada apa yang konsumen tonton (watch) dan beli (buy), pertumbuhan belanja iklan menunjukkan trend yang positif dari tahun ke tahun.

Berangkat dari fenomena tersebut, penelitian ini bertujuan untuk mengetahui apa bentuk marginalisasi ojek pangkalan yang terdapat pada iklan Grab dengan tagar \#PilihAman. Dengan demikian, penelitian ini bertujuan untuk melihat marginalisasi terhadap ojek pangkalan yang dinilai tidak menjamin keselamatan penumpang. Hal ini dikarenakan iklan Grab \#PilihAman dipandang menuai kontroversi dan menjadi perbincangan.

\section{METODE PENELITIAN}

Jenis penelitian yang digunakan dalam penelitian ini adalah deskriptif kualitatif dengan paradigma kritis. Metode Penelitian kualitatif adalah penelitian yang digunakan untuk meneliti pada kondisi objek alamiah, dimana peneliti merupakan instrumen kunci (Sugiyono, 2005). Perbedaannya dengan penelitian kuantitatif adalah penelitian ini berangkat dari data, memanfaatkan teori yang ada sebagai bahan penjelas dan berakhir dengan sebuah teori. Secara lebih operasional, penelitian ini menggunakan metode semiotika untuk menganalisis obyek penelitian. Obyek penelitian dalam penelitian ini adalah iklan Grab versi pilih aman tahun 2018 yang berdurasi 46 detik. Obyek penelitian ini dianalisis dengan menggunakan analisis semiotika Roland Barthes yang mengembangkan pemikiran dari Ferdinand De Saussure. 
Pertama, tanda (sign) terdiri dari dua aspek, yaitu penanda (signifiant), dan petanda (signified). Penanda dapat dimengerti sebagai bentuk/wujud fisik. Penanda bisa berupa bunyi, gambar, huruf, visual dan sejenisnya. Sedangkan petanda adalah konsep atau arti dari apa yang ditandai. Relasinya antara keduanya bersifat "diada-adakan" (arbitrary), yang berarti tidak ada relasi yang sifatnya alamiah antara penanda dan petanda. Namun demikian, relasi yang bersifat "diada-adakan" terikat oleh konvensi atau struktur. Penjelasan selanjutnya akan menjelaskan tentang hal ini. Secara etimologis, Saussure menyebutkan bahwa semiotika sebagai ilmu yang mengkaji tentang tanda sebagai bagian dari kehidupan sosial (Piliang, 2003). Selanjutnya Saussure, semiotika kemudian dielaborasi sebagai hubungan tripartit yakni tanda (sign) yang merupakan gabungan dari penanda (signifier) dan petanda (signified) (Fiske \& Hartley, 1996).

Kedua, langue dan parole. Langue adalah abstraksi dan artikulasi bahasa pada tingkat sosial budaya, sedangkan parole merupakan ekspresi bahasa pada tingkat individu. Langue bisa kita sebut sebagai sistem bahasa yang berlaku, sedangkan parole adalah bagaimana individu berbahasa dalam sistem tersebut. Roland Barthes melanjutkan pemikiran Saussure dengan memberi telaah pada interaksi antara teks dengan pengalaman personal dan kultural penggunanya. Interaksi antara konvensi dalam teks dengan konvensi yang dialami dan diharapkan oleh penggunanya. Gagasan Barthes ini dikenal dengan tatanan penandaan (order of signification), yang mencakup primary signification atau denotasi (makna sebenarnya sesuai kamus) dan secondary signification atau konotasi (makna ganda yang lahir dari pengalaman kultural dan personal). Makna konotasi ini yang kemudian menjadi berkembang menjadi mitos. Dalam penelitian ini, penulis berusaha melakukan analisis semiotika, mulai dari primary signification sampai secondary signification pada iklan Grab versi \#PilihAman.

\section{HASIL DAN PEMBAHASAN}

Setelah dilakukan penelitian menggunakan teori semiotika dan dalam aspek denotasi Grab dengan penggunaan hashtag \#PilihAman yang digunakan oleh perusahaan moda transportasi online Grab pada detik ke-44 dalam iklan ini konotasinya (Grab menjamin keamanan para pengguna atau penumpang Grab. Hal tersebut mempengaruhi pemilihan moda transportasi ojek yang awalnya dari ojek pangkalan yang hanya ditemui di tempat-tempat tertentu (pangkalan) beralih menjadi ojek online yang bisa dipesan melalui aplikasi dan titik penjemputannya bisa dimana saja (kecuali zona merah). Selain itu tagar \#PilihAman juga menyampaikan pesan bahwa Grab menawarkan sistem keamanan bagi pelanggannya lebih dibandingkan dengan ojek pangkalan. Dengan begitu terlihat jelas bahwa iklan Grab dengan tagar \#PilihAman memarginalisasi ojek pangkalan dengan tersirat (tergambar) terlihat dari iklan yang ditampilkan.

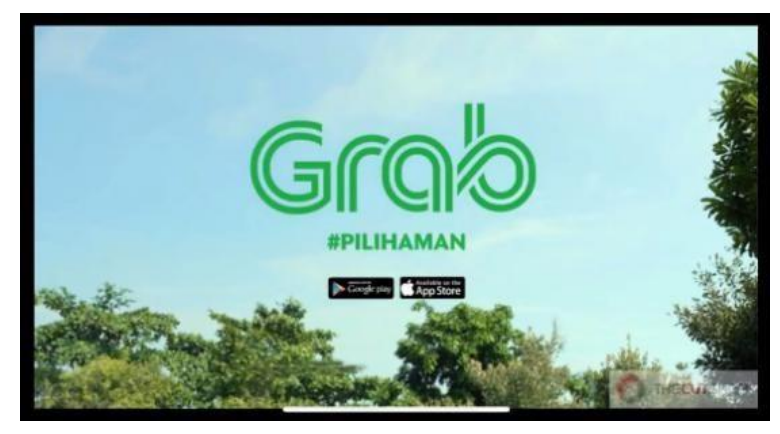

Gambar 1. Tangkapan layar pertama iklan Grab

Selain itu juga sejak adanya tagar \#PilihAman mindset dari sebagian besar konsumen ojek tertanam bahwa ojek online khususnya Grab memiliki lebih banyak keunggulan dibandingkan ojek pangkalan terutama dalam segi keamanannya. Padahal dalam kenyataan atau realitanya kemanan bergantung pada pengemudi itu sendiri, bagaimana cara dia berkendara, cara dia menghargai pengendara lain di 
jalan. Tidak sedikit juga ojek online yang berkendara secara ugal-ugalan dan membahayakan penumpang atau konsumen serta pengguna jalan lain.

Dalam aplikasi Grab menampilkan informasi mengenai identitas pengendara untuk menambah segi keamanan seperti foto, nama, dan nomor telepon. Identitas ini ditampilkan agar calon penumpang dapat mengetahui armada yang melayani pesanannya, nomor telepon driver yang disediakan berguna apabila pengguna ingin mengubungi driver tersebut baik melalui telepon atau SMS (Short Message Service), tetapi banyak dari driver tersebut yang identitasnya tidak sesuai dengan yang dipesan (digantikan oleh orang lain). Hal tersebut tentunya dapat dibilang tidak semua Grab aman dalam segi data informasi pengemudi.

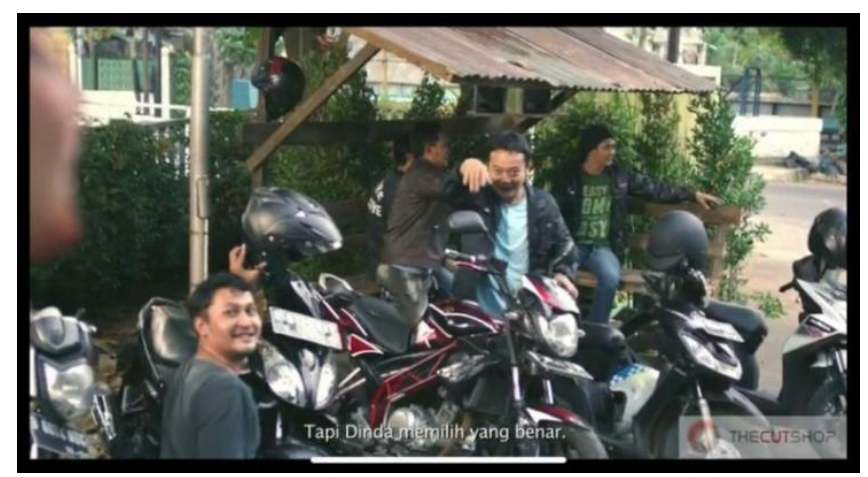

Gambar 2. Tangkapan layar kedua iklan Grab

Temuan lain yang menjadi gambaran kelebihan dari iklan Grab dengan tagar \#PilihAman yang memarginalisasi ojek pangkalan adalah menjual kata-kata lebih aman. Dari gambar di atas yang diambil pada iklan detik ke-25 konotasinya ojek pangkalan sedang memanggil Dinda tetapi tidak diperdulikan dan setelah itu memilih memesan Grab menggunakan aplikasi. Denotasinya ojek pangkalan yang tidak menggunakan cara sopan dan suka membujuk keras konsumen atau calon penumpang agar mau untuk naik ojek pangkalan. Dengan kata-kata "tapi Dinda memilih yang benar" menyudutkan ojek pangkalan bahwa ojek pangkalan bukan pilihan yang benar tetapi Grab-lah pilihan yang tepat. Padahal tidak ada salahnya untuk memilih ojek pangkalan untuk dijadikan transportasi karena tidak harus menunggu, dalam video tersebut terlihat terdapat pangkalan ojek didepan Dinda. Calon penumpang tidak perlu menggunakan perangkat seluler untuk memesan ojek pangkalan tidak perlu menggunakan smartphone atau aplikasi ojek online, jika ingin naik ojek bisa mencari pangkalan ojek terdekat.

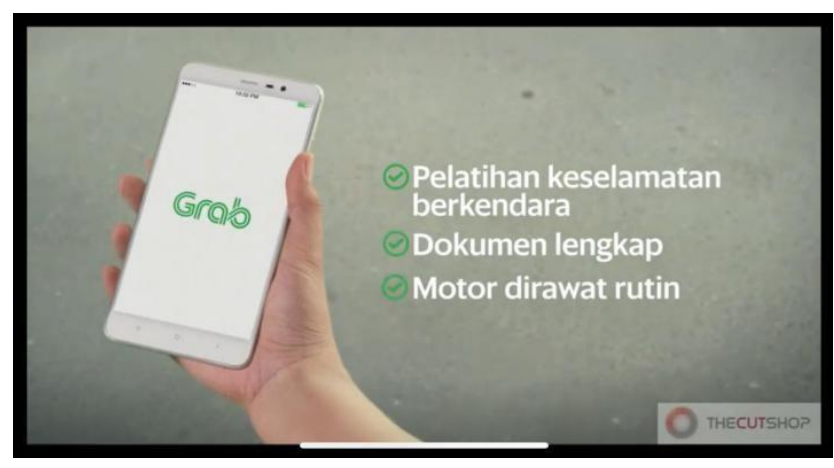

Gambar 3. Tangkapan layar iklan Grab

Disini dapat kita pada detik ke-32 konotasinya Grab memiliki fasilitas pelatihan keselamatan berkendara, dokumen lengkap dan motor dirawat rutin. Denotasinya ojek pangkalan, seolah-olah ojek pangkalan tidak memiliki sistem keamanan dalam berkendara yang baik ketika mengantarkan 
konsumennya ke tempat tujuan, padahal pada kenyataannya keamanan dalam berkendara itu sendiri banyak terdapat faktor-faktor di luar faktor human recources. Dan kata "dokumen lengkap" menyudutan ojek pangkalan padahal belum tentu ojek pangkalan tidak memiliki dokumen yang lengkap. Kata "motor dirawat rutin" seolah-olah menggambarkan bahwa ojek pangkalan tidak merawat motornya dengan rutin. Iklan tersebut sangat mempengaruhi pola pikir banyak orang di luar sana tentang perbandingan antara ojek online dan ojek pangkalan, disitulah marginalisasi ojek pangkalan yang dilakukan oleh Grab terjadi dan dinilai merugikan serta menjatuhkan citra ojek pangkalan yang sebelumnya begitu dekat konsumennya (masyarakat).

Fasilitas juga merupakan tolak ukur karena apa yang diberikan Grab ini tidak ditemukan oleh ojek pangkalan. Fasilitas tertentu yang dimaksud adalah komponen fisik dari sistem yang ditentukan dalam ruang dan menyusun jaringan penghubung dan titik-titik simpul system transportasi, sistem control adalah terdiri dari kendaraan dan kontrol arus (Setijowarno, 2003). Fasilitas sebagai bentuk keamanan yang diberikan oleh Grab karena membantu mobilitas masyarakat dalam beraktifitas. Dengan munculnya ojek online ini membuat munculnya perspektif ojek pangkalan terhadap ojek online.

"jumlah pelanggan setelah hadirnya ojek online itu membuat kami para pengemudi ojek pangkalan sepi pelanggan, mas. Dulu sebelum gojek apa grab datang pelanggan kami banyak, ibu-ibu pergi ke pasar, atau anak sekolah, juga kadang-kadang ada pelanggan yang tujuannya jauh-jauh. Tapi sekarang ya, sepi begini mas." (Ari, 42, Pengemudi Ojek Pangkalan, 3 Juli 2017)

Ojek pangkalan biasanya hanya digunakan oleh orang-orang yang tidak bisa menggunakan teknologi atau orang-orang yang sudah berumur. Marginalisasi kepada ojek pangkalan sebenarnya tidak akan terjadi jika peraturan dan hukum jelas untuk melindungi pengemudi dan penumpang dari berbagai macam ancaman yang mungkin saja terjadi, maka diskriminasi terhadap kelompok tertentu seperti ojek pangkalan ini minim terjadi.

Salah satu sumber utama konflik dan kekerasan di berbagai daerah adalah kondisi penegakan hukum di Indonesia yang sangat lemah. Ditambah lagi dengan berbagai bentuk diskriminasi dan marginalisasi dalam pengaturan social, ekonomi, politik, dan pemanfaatan sumber daya alam bahkan kehidupan budaya. Berbagai perasaan ketidakadilan dan ketidakpuasan umum pun berkecamuk dan meledak menjadi tragedi kemanusiaan yang sangat memilukan dan mengerikan (Ali, 2018).

Angkatan umum dalam bentuk online yang diterima masyarakat sebagai sarana yang memudahkan dan beroprasional ditengah pengguna jalan lain. Perlindungan kepada pengguna jalan dari angkutan umum online harus diberikan karena Indonesia berdasarkan negara hokum. Indonesia berdasarkan atas hukum (Rechsstaat) tidak berdasarkan atas kekuasan belaka (Machtsstaat). Asas ini mengandung makna yang amat dalam dalam kehidupan bermasyarakat dan bernegara karena ini berarti bahwa negara (termasuk di dalamnya pemerintah, lembaga-lembaga negara, dan lembaga pemerintah serta a paratur negara) dalam melaksanakan tugasnya senantiasa harus mendasarkan diri pada hukum dan keadilan (Ilhami Bisri, 2014).

Dari hasil pembahasan diatas fenomena yang terjadi setelah adanya tagar \# PilihAman antara lain: (1) peningkatan jumlah driver ojek online, (2) berkurangnya minat konsumen ojek terhadap ojek pangkalan, (3) berkurangnya jumlah pendapatan driver ojek pangkalan, (4) banyaknya pandangan negatif konsumen terhadap ojek pangkalan. Pernyataan di atas didapat dari hasil wawancara langsung dengan beberapa pengemudi ojek pangkalan, konsumen ojek dan pengamatan lapangan secara langsung.

Para pengendara ojek pangkalan menganggap bahwa adanya ojek online sebenarnya merusak pasaran harga atau tarif ojek. Oleh karena itu, para penumpang yang biasanya menggunakan jasa ojek pangkalan telah banyak yang beralih menggunakan ojek online. Para pengendara tersebut tidak menawarkan tarif yang berlebihan pada calon penumpang agar para calon penumpang masih mau menggunakan jasa ojeknya. Oleh karena itu, mereka tidak bisa menawarkan jasa ojeknya dengan tarif 
yang lebih mahal atau tarif yang seperti biasanya. Para pengendara ojek juga menawarkan jasa lain selain jasa ojek. Jasa yang ditawarkan oleh pengendara ojek pangkalan yaitu menganar barang atau biasa disebut kurir.

\section{KESIMPULAN}

Berdasarkan temuan dan diskusi dalam penelitian ini, iklan Grab \#PilihAman telah memarginalisasi ojek pangkalan melalui beberapa hal. Pertama, Grab \#PilihAman juga menyampaikan pesan bahwa Grab menawarkan sistem keamanan bagi pelanggannya lebih dibandingkan dengan ojek pangkalan. Kedua, adanya informasi pengemudi yang tertera di layar aplikasi penumpang membuat Grab semakin ingin meyakinkan konsumen bahwa Grab adalah sarana yang dianggap terbuka dan meyakinkan secara personal mengenai sumber daya manusia. Ketiga, adanya bentuk marginalisasi kendaraan yang tidak dirawat oleh para pemilik motor dari ojek pangkalan, sehingga seolah-olah Grab adalah pilihan yang dipastikan aman karena adanya pemeriksaan secara berkala.

\section{REFERENSI}

Affandi, Mochammad Arif. (2017). Strategi Adaptif Pengendara Ojek Pangkalan Dalam Menghadapi Persaingan Dengan Ojek Online Di Stasiun Gubeng Lama Surabaya. Universitas Negeri Surabaya.

Alamona, Junaivan, John D. Zakarias and Eveline J.R.Kawung. (2017). Marginalisasi Gender Dalam Pengambilan Keputusan (Studi Kualitatif Kaum Perempuan Di Lembaga Legislatif Kota Manado). Universitas SamRatulangi, 20, 3-4.

Amajida, Fania Darma. (2016). Kreativitas Digital Dalam Masyarakat Risiko Perkotaan: Studi Tentang Ojek Online “Go-Jek” Di Jakarta. Informasi, 46(1).

Bahari, Yohanes. (2010). KARL MARX: Sekelumit Tentang Hidup dan Pemikirannya. Jurnal Pendidikan Sosiologi dan Humaniora, 1(1).

Bayti, Rahmania Nur. (2018). Paguyuban Ojek Pangkalan (StudiKasus Tindaan Sosial Ojek Pangkalan Dalam Menghadapi Persaingan dengan Ojek Online). Diss. Universitas Airlangga.

Fathy, R. (2018). Modal Sosial Ojek Pangkalan: Adaptasi Terhadap Aplikasi Online Transportasi Publik. Masyarakat dan Budaya, 20(2).

Indriani, SriSeti, Lilis Puspitasari, and Evi Rosfiantika. (2019). Analisis Interaksi Simbolik Pada Konten Ofensif Iklan Grab \#pilihaman. ProTVF, 3(1).

Kriyantono, Rachmat. 2013. Manajemen Periklanan: Teori dan Praktik. Malang: Universitas Brawijaya Press.

Lupiyodi, Rambat. 2013. Manajemen Pemasaran Jasa. Jakarta: Salemba Empat

Martinouva, Rissa Afni. (2019). Perlindugan Hukum Pengguna Jalan Dari Angkutan Umum Online Pada Pengguna Telepon Saat Mengemudi Kendaraan. Pranata Hukum, 14(2).

Mar'ati, Nafisa Choirul and Tri Sudarwanto. (2016). Pengaruh Kualitas Layanan Dan Harga Terhadap Kepuasan Pelanggan Jasa Transportasi Ojek Online (Studi Pada Konsumen Gojek di Surabaya). Universitas Negeri Surabaya.

Purwanto, Andhika Cahya, Asma Luthfi, and Thriwarty Arsal. (2018). Eksistensi Ojek Pangkalan Didalam Perkembangan Transportasi Berbasis Informasi Dan Teknologi. Solidarity: Journal of Education, Society and Culture, 7(1).

Sukmono, Junaedi. 2014. Komunikasi Multikultur. Yogyakarta: Buku Litera Yogyakarta. 